\title{
The Population Health OutcomEs aNd Information Exchange (PHOENIX) Program - A Transformative Approach to Reduce the Burden of Chronic Disease
}

\author{
Steven J. Korzeniewski ${ }^{1}$, Carla Bezold ${ }^{2}$, Jason T. Carbone ${ }^{1}$, Shooshan Danagoulian1, Bethany \\ Foster ${ }^{1}$, Dawn Misra' ${ }^{1}$, Maher M. El-Masri ${ }^{1}$, Dongxiao Zhu ${ }^{1}$, Robert Welch ${ }^{1}$, Lauren Meloche ${ }^{1}$, \\ Alex B. Hill ${ }^{1}$, Phillip Levy ${ }^{1}$ \\ ${ }^{1}$ Wayne State University, ${ }^{2}$ Detroit Health Department
}

\begin{abstract}
This concept article introduces a transformative vision to reduce the population burden of chronic disease by focusing on data integration, analytics, implementation and community engagement. Known

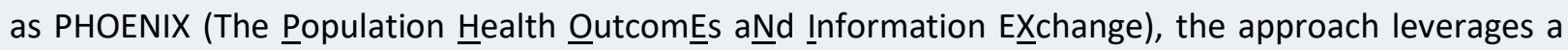
state level health information exchange and multiple other resources to facilitate the integration of clinical and social determinants of health data with a goal of achieving true population health monitoring and management. After reviewing historical context, we describe how multilevel and multimodal data can be used to facilitate core public health services, before discussing the controversies and challenges that lie ahead.

Keywords: Health information exchange; data integration; epidemiology; electronic health record; translational science; social determinants of health.

Correspondence: *skorzeni@med.wayne.edu

DOI: 10.5210/ojphi.v12i1.10456

Copyright @2020 the author(s)

This is an Open Access article. Authors own copyright of their articles appearing in the Online Journal of Public Health Informatics. Readers may copy articles without permission of the copyright owner(s), as long as the author and OJPHI are acknowledged in the copy and the copy is used for educational, not-for-profit purposes.
\end{abstract}

\section{Introduction}

Despite tremendous investment in research [1] and having the greatest annual healthcare expenditure per capita [2], population-level health indices are poorer in the US compared to peer high-income countries [3,4]. Life expectancy declined in the US for the first time in nearly a quarter century in 2015 [5] and then again in 2016 [6]. Cardiovascular disease (CVD) is the leading cause of death in the US [7] and hypertension accounts for the largest fraction of attributable risk [8]; however, most of the variation in mortality can be traced to social, behavioral and metabolic factors [8].

The most vulnerable among us suffer the greatest burden of chronic diseases with increasing socioeconomic inequalities widening health disparities $[9,10]$. Consequently, there is great interest 
in the ability to integrate data on social determinants of health with clinical information available from electronic health records [11-13]. Multiple funding agencies are also focusing on data integration beyond these sources, highlighting key information compiled by public health and social service organizations as well as community stakeholders [14]. Despite such interest, few programs have demonstrated the capacity to build the necessary networks or resolve technical barriers that limit health information exchange (HIE) impact. While emerging approaches prompt excitement [15,16], additional research is necessary [17-20].

Included among the approaches garnering enthusiasm is the concept of research universities working with health systems, governmental entities, and non-governmental organizations in collaboration to address the challenges of massive data amalgamation [21]. By serving as impartial stewards of health information, conducting research to address knowledge gaps and disseminating information about best practices, research universities can be pivotal institutions in this effort. Research universities are ideally positioned to help bring about a new golden era of chronic disease prevention that will use multidimensional and multimodal geospatial data to inform the work of public health and social service agencies. Indeed, we agree that academia can play a key role specifically in improving public health practice capacity via systemwide cross-sector collaboration (akin to existing collaborations between academia and industry, healthcare and national health research agencies) [22]. In what follows, we review historical context and introduce a transformative vision to reduce the population burden of chronic disease by focusing on analytics, implementation and community engagement. Known as PHOENIX (The Population Health

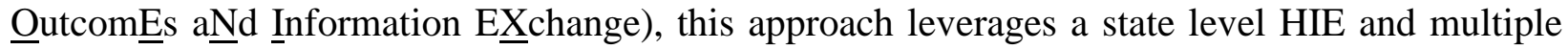
other resources to facilitate the integration of clinical and social determinants of health information with a goal of achieving true population health management.

\section{Historical Context}

\subsection{The Golden Era of Chronic Disease Epidemiology}

Sanitation during the first half of the $19^{\text {th }}$ century and infection-control efforts through the first half of the $20^{\text {th }}$ century achieved unprecedented improvements in population health [23]. As infectious disease epidemics subsided in much of the developed world, a focus on noncommunicable diseases emerged [24]. On the heels of World War II, major investments in science, medical and public health research ushered in a "Golden Age" of chronic disease epidemiology [25]. The recognition of tobacco as a carcinogen prompted new public health policies and cultural norms. Effective treatments were developed for leading causes of mortality. In turn, progress in prevention of chronic diseases contributed to a dramatic increase in U.S. life expectancy (see [26] for a review).

The chronic disease era of epidemiology was inspired by the sanitarian notion that 'mass disease' occurs when 'society is out of joint' [26]. That is, when social disruptions result in crowded living situations, exposure to harmful substances, inequitable distribution of resources, and other harmful conditions. Classic studies during the 1940s-50s categorized CVD as a 'mass disease' based on tenfold international variation of prevalence. Subsequent investigations linked the global variation to differences in saturated fat intake, serum cholesterol and hypertension; smoking was also recognized as a key contributor. These findings inspired public health programming during the 1960s-70s directed at prevention of CVD. Better therapies for hypertension were introduced in the 
1980s and statins followed in the 1990s to address high cholesterol. By year 2000, CVD incidence had declined by approximately $70 \%$ compared to 1968 [27]. However, the trends appear to be stagnating as age-adjusted mortality rates increased in the U.S. from 2000-to-2017 for both males and females ages 35-74 years [28-30].

\subsection{Rising Health Inequalities}

While U.S. premature mortality rates declined from 1966 to 1980 in all socioeconomic strata defined by county income quintile and race/ethnicity, relative health inequities between whites and people of color widened over the next two decades [31]. County-level differences in life expectancy also increased from 1980- to- 2014, and hypertension among residents age $\geq 30$ years accounted for $62 \%$ of the variation [9]. These changes were primarily mediated by correlates of social disadvantage, particularly behavioral and metabolic risk factors [8,9]. In short, 'Place Matters' [32], especially for hypertensive heart disease as seen in the fourfold difference between U.S. counties with top and bottom decile mortality rates [33]. Hypertension remains a 'mass disease' in the modern era and vulnerable groups are severely impacted.

Health disparities are primarily driven by differences in social determinants (e.g., poverty, inadequate access to healthcare and nutritious foods, chronic stress, etc.). However, much remains unknown about how pathophysiology is affected by social factors and their correlates (e.g., lifestyle changes, urbanization, migration and acculturation), especially for hypertension. Consequently, modern frameworks call for multilevel systems approaches that pay attention to both societal- and molecular-level contributors to health equity (i.e., "the absence of unfair and avoidable or remediable differences in health among social groups" [34]) [35,36].

\subsection{The Precision Medicine Paradox}

History shows that health agendas tend to sway back and forth between medical care and primary prevention approaches [37]. During the waning years of the chronic disease era of epidemiology (1950-2000), the focus shifted towards technology and clinical care. This shift appears to have been driven by a revived form of genetic determinism (see [38] for a review). Despite upwards of ten billion dollars of public funding in the U.S. alone, genomic research has not yet translated into substantial gains in population-level health outcomes [39-41]. Nor has genomics made a substantial contribution to our understanding of population-level racial health disparities (e.g., in CVD [42]). Less than $1 \%$ of published genomics studies have progressed beyond basic science or preclinical research [43]. In short, there is an 'evidence dilemma' supporting the role of genomics in clinical practice and public health $[39,44]$. This translation gap has been described as a 'valley of death' [45] that underlies the modern 'paradox of precision medicine' [46,47]; i.e., increasing technological capacity followed by decreasing application towards public health improvement.

\subsection{Pivot Towards Public Health \& Epidemiology}

Efforts to fill the translation gap described above have intensified in the U.S. with the launch of the Precision Medicine Initiative and the "All of Us" research program [48]. The Precision Medicine concept has responded to criticisms by adopting principles of public health [49] and recognizing epidemiology as "a fundamental building block of the translational research enterprise" [50]. This shift prompted the Health Department of Western Australia to coin the term 
"Precision Public Health" in 2013 [51]. Analogous to the aims of Precision Medicine, Precision Public Health seeks to provide the right interventions at the right place and time to the right population [52]. A key pivot is the increasing focus on implementation science and descriptive epidemiology [53], as Precision Public Health “... requires robust primary surveillance data, rapid application of sophisticated analytics to track the geographical distribution of disease, and the capacity to act on such information" [54]. So-called "Big Data" integration is another key element $[49,55-57]$, though much of the discussion is theoretical.

The relevance of surveillance [58] and the importance of program evaluation [59] are not new to public health. What is new is the modern landscape of health information. Challenges presented by the unprecedented amount and complexity of data include: i) technical difficulties accessing, integrating and sharing health information across multiple domains [60,61] and modalities [62]; ii) ethical [63] and epistemological concerns [64-66]; iii) implications of data inaccuracies and selective measurement in routinely collected data [67,68]; and iv) a growing potential for spurious correlations in large datasets $[55,65,69]$. In turn, a strong foundation in surveillance and descriptive epidemiology is needed to establish an iterative process for interpreting what we know and what we don't know from within and across scientific disciplines (and public health sectors) [55].

There is increasing focus on small-area analytics to assess the local burden of disease (e.g., www.healthdata.org/lbd) and promote effective targeting and uptake of evidence-based interventions [67]. That is, identifying county-level [70] or city-level [71] health disparities that may be masked in national metrics can inspire strategic public health action. For example, a recent study provided evidence of strong geographic differences in cardiovascular health across the U.S. by using linked 'micromap' plots and multilevel logistic regression models to analyze crosssectional vital statistics and administrative data [72]. Importantly, status as a racial minority or low socioeconomic status explained $51 \%$ of the variation, while state-level factors accounted for an additional $28 \%$ (e.g., soda drink taxes, farmers markets, convenience stores). Due to the spatiotemporal properties of social determinants of health, longitudinal studies are needed to better understand how the dynamics between societal factors, built and natural environments and individual-level characteristics contribute to health equity. Equally important are finer-scale geospatial analyses to inform local public health programming and connections with clinical care [73]; e.g., by developing 'community vital signs' [74] and linking social determinants and service information to electronic health records [11]. Fortunately, the recent technical advances have generated a massive amount of spatiotemporal data across multiple modalities at a much finer scale and resolution $[75,76]$. 


\section{Where do we go next? An introduction to PHOENIX - The Population Health OutcomEs aNd Information Exchange (Fig. 1)}

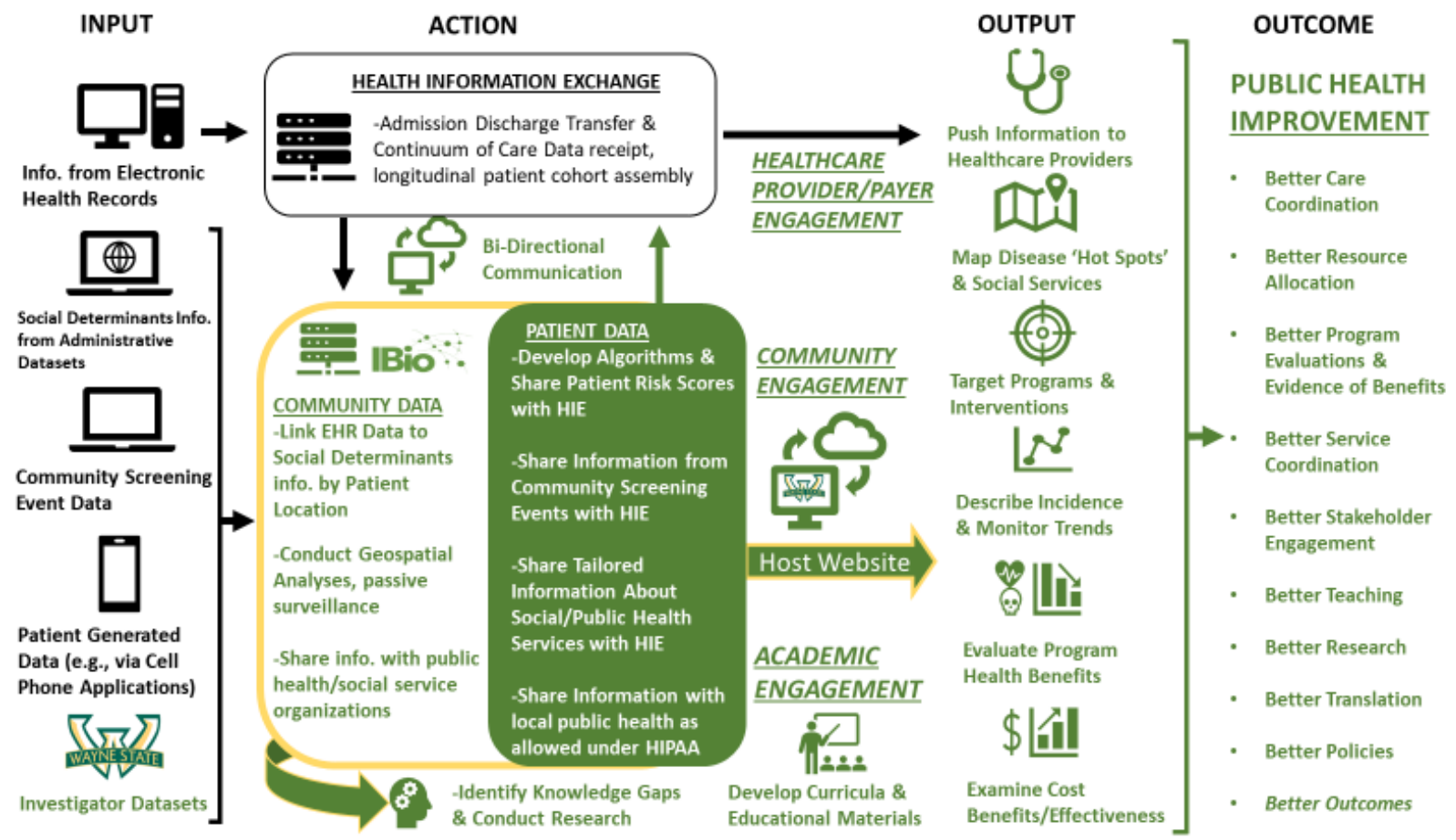

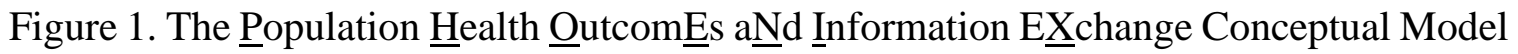

\subsection{Overview}

We do not suffer from a lack of information. Health care systems, researchers, government agencies, and not-for-profits collect and warehouse masses of data. However, these databases do not interact smoothly; it is labor intensive and often cost prohibitive to blend the information together. Privacy laws also add a layer of complexity. Therefore, existing data are not routinely shared among institutions, community members and researchers. While some repositories hold invaluable information, no single source integrates data to convey a timely snapshot of local factors that are related to health equity and outcomes. As a result, data for public health action are fragmented, incomplete, and typically lag by months or even years. Consequently, programs and interventions are often guided by intuition rather than evidence. To address this, Wayne State University (WSU) is developing PHOENIX - the first shared data repository of its kind in Michigan.

\subsection{Public Health Data Commons}

Supported by a grant from the Michigan Health Endowment Fund (MHEF), the PHOENIX program design is informed by the NHLBI framework for community-engaged implementation research and action towards health equity [14,77]. Beginning with a focus on Southeast Michigan and the metro Detroit region, we are addressing critical challenges identified by NHLBI by creating a public health data commons and providing a mechanism for coordinated access to multidimensional health information (Table 1). We are working with internal partners at WSU to 
catalog existing datasets, codebooks and instructions on pursuing collaboration with investigators who maintain these resources. In parallel, we are collating publicly available administrative datasets and codebooks, either directly (e.g., using Google Map and Places Application Programming Interfaces (APIs)) or by working with independent contractors (e.g., Loveland Technologies). The backbone of our shared data infrastructure is our relationship with two large HIEs that will provide targeted information from electronic health records (EHRs) statewide: the Michigan Health Information Network (MiHIN) and Great Lakes Health Connect (GLHC). These two entities, which recently merged, provide complementary access to information from every health system and a large number of ambulatory care clinics in the state of Michigan, with data linkage at the individual patient level across healthcare settings.

\section{Table 1. Example Data Targeted by PHOENIX}

\section{Social environment \& Clinical Information}

Electronic Health Records shared by Michigan Health Information

Exchanges

State of Michigan Vital Statistics
US Census/ American Communities Survey
Uniform Crime Reports
WSU Investigator Databases
National Center for Education Statistics
Patient/Resident Generated Health Data

\section{Built environment (e.g., Points of Interest)}

Neighborhood Characteristics

Healthcare Resources

Grocery Stores, Restaurants, Liquor Licenses

Schools and Daycare Facilities

Places of Worship

Parks, Sidewalks, Alleys

Tax Status, Foreclosures, Blight Violations, Occupancy

Transportation and Mobility

\section{Natural environment}

Environmental Protection Agency Data (e.g., Air \& Water Pollution-Particulate Matter)

Climate (Satellite Images)

\section{Policy Environment}

Blight Removal Program

Rental Registration Compliance 
As a first step, MiHIN has agreed to secure modified Business Associate Agreements (BAAs) to enable data sharing with PHOENIX. Once done, MiHIN will then create a data lake using information (e.g., vital signs, laboratory test results, body mass index, medications, social history, diagnosis codes) contained within Admission Discharge and Transfer (ADT) alerts and Continuity of Care Documents (CCD) for PHOENIX to access. These data will be de-identified but linked at the patient level by a common key identification number. Further, home addresses will be converted to geographic indicators enabling data aggregation at the ZIP code, census tract, and census block level (as admissible based on prevalence under local, state and national public health policies). While details of the merger with MiHIN are being worked out, GLHC has maintained a patient-level longitudinal cohort since 2009 that is continuously updated with ADT and CCD information for all new healthcare encounters. By leveraging this resource PHOENIX will be able to access historical data and establish robust time-trends. Key to the PHOENIX program applications is that MiHIN/GLHC have already standardized/integrated data elements received from different health systems, created an anonymized unique patient identifier across systems and established portals to push/pull information to an array of different end-users across the state.

\subsection{Applications}

PHOENIX will model the type of HIPAA-compliant, cloud-based and integrated data infrastructure needed to leverage state-wide HIEs towards public health surveillance, community risk stratification, community engagement and program evaluation - an overarching purpose far more evolved than optimization of individual patient care data as in typical HIEs [78]. MiHIN and GLHC provide invaluable services by receiving and coordinating EHRs from providers statewide. The PHOENIX program will complement these efforts by integrating social determinants information from multiple administrative datasets to create and share community as well as patient risk stratification scores. This will also foster more direct collaboration between health care providers, social services and public health organizations, and other community stakeholders.

\subsubsection{Mapping Disease Burden 'Hot Spots'}

As we have shown with a beta version of PHOENIX [79], one of the most accessible utilities of our shared data infrastructure will be to determine and monitor the incidence of targeted conditions that are deemed important by community stakeholders. During a recent community-engaged health assessment the Detroit Health Department identified the need for timely, locally relevant data regarding chronic conditions such as asthma as a surveillance priority for community members and public health partners. Current estimates of asthma burden in Detroit and surrounding communities typically rely on information from the Michigan Behavioral Risk Factor Surveillance System (MiBRFSS). However, the MiBRFSS was not designed to be representative of the Detroit area. Because Michigan residents are mostly white and Detroit residents are mostly black, and because the latter disproportionately suffer asthma, the disease burden in Detroit is underestimated by MiBRFSS. The MiBRFSS is also not designed to capture neighborhood level variation in asthma, and there is a lag of more than a year in availability of data. PHOENIX will provide timely, relevant information about emergency department visits and hospital admissions for asthma at the ZIP code, census tract or census block level. Because MiHIN and GLHC accrue data on a daily basis, this approach will enable rapid 'hot-spot' identification and facile evaluation of potential intervention outcome benefits. By also overlaying social determinants information, we can conduct geospatial analyses to better understand interrelationships and design interventions that are specific 
to community needs. We will similarly target additional health concerns that account for major fractions of morbidity and mortality and are deemed important by community members. To that end, we have particular interest in understanding how blood pressure impacts CVD risk, and how social determinants affect related health outcomes.

\subsubsection{Patient-Level \& Community-Level Risk Classifications}

Recently, a machine learning algorithm using key indicators of social disadvantage, behavior and environmental conditions obtained from publicly available data sets explained about $70 \%$ of U.S. county-level variation in premature mortality [80]. Machine learning modeling of data in EHRs can also predict intermediate outcomes with a fair degree of accuracy (e.g., emergency admission within 24 months [81], one-year incident hypertension [82], and left ventricular hypertrophy [83]). Use of longitudinal information enhances prediction performance compared to cross-sectional models [84-86]. Similar results have been produced using large clinical research datasets [87,88], with advanced deep learning techniques [89], and with classical regression techniques [90-92]. These types of information can be shared by HIEs. For example, a recent study provided evidence that risk scores developed using a combination of EHR and community data can identify patients in need of wraparound services for social determinants and sharing this information with providers appears to have increased referrals and uptake $[16,93]$.

The PHOENIX program will develop patient-level and community-level risk stratification models for identifying susceptibility to target conditions and service needs. These models will integrate information about social, built, natural and policy environments using HIPAA-compliant information shared by MiHIN and GLHC through the data lake created for PHOENIX. We will develop novel solutions for specific risk classification problems by using hierarchical models, multiple machine learning algorithms (e.g., random tree forest, neural networks) and classical techniques based on evidence from previous studies including approaches employed Global Burden of Disease study group, as appropriate. We will also adapt novel methods that involve community members in quantitatively weighting the importance of specific health topics [15]. Community risk scores will be shared via the PHOENIX website; future efforts will emphasize incorporation of such risk scores into provider workflows either directly through their EHR or indirectly via secure web-based applications.

\subsubsection{Public Health Program Targeting \& Evaluation}

The PHOENIX program will host a custom-made interactive website to share health information with a broad array of community stakeholders. Users will be able to, i) map the incidence of targeted conditions and upstream risk factors, ii) overlay social determinant information about natural, built, social and policy environments, iii) make basic comparisons between communities, and iv) crudely estimate health equity impact and economic benefits of programs and policies that lessen the burden of disease. Providing this information to community stakeholders will enhance their capacity to seek support and target interventions towards areas in greatest need. PHOENIX will provide community stakeholders with a unique resource to evaluate program and policy benefits guided by the CDC Framework for Program Evaluation [59]. We will also leverage shared data to investigate changes in health equity indicators as a function of community revitalization activities (e.g., blight removal, expansion of public-private partnerships for violence prevention, 
etc.). Over time, PHOENIX will iteratively enable better evaluations and stronger partnerships that focus on data-driven goals.

\subsubsection{Benefit-Cost and Economic Analyses}

PHOENIX will also include information about medical expenditures and indirect but associated societal costs to motivate investments that improve health equity. We can estimate potential costsavings if community exposures are removed or protective factors are enhanced. PHOENIX will do just that while also providing a mechanism to share information with policymakers and other stakeholders in order to motivate community investments that improve health equity.

\subsubsection{Expanding Reach Through Education}

Academic health centers are poised to lead the way in public health sciences, pioneering evaluation and implementation strategies [21]. Specifically, academic health centers can leverage university resources and influence as neutral brokers of knowledge about the value, benefits, risks and costs of precision public health to cultivate community-wide understanding of ethical, legal and social implications [21]. Engaging university expertise in medicine, epidemiology, health services research, environmental science, sociology, economics, health marketing, urban design, political science and other disciplines can address complex barriers to population health improvement.

The PHOENIX program will specifically address another critical challenge identified by NHLBI: education and training of the broader local biomedical community. We propose to develop educational materials, establish curricula and develop tools to enhance training. Cultivating an appreciation of social determinants of health is particularly important -- a stance supported by the American Medical Association's Accelerating Change in Medical Education Consortium. The PHOENIX team will do this in part by enlisting medical students and fellows to collate information about social services that are available in local communities (as described in [94]), cataloging social determinants screening tools, and conducting prospective research and secondary data analyses. Equally imperative are steps to increase health and statistical literacy among clinicians and patients alike as we move into the so-called "Big Data" era [95-97]. The public health data commons managed by PHOENIX and community outreach initiatives will also provide ample opportunities for students to conduct secondary data analyses, develop health messaging materials, evaluate programs and estimate cost benefits. PHOENIX will also be connected with a biobank and clinical data registry under development at WSU.

\subsubsection{Community Engagement}

A strength of the PHOENIX project is its capacity to build on existing WSU-community collaborations. In 2015, WSU established the Office for Community Engaged Research (OCEnR) under the Office for the Vice President of Research. For the PHOENIX project, OCEnR will engage the community through open dialogue to determine needs and employ community members to help implement targeted initiatives. OCEnR is focused on sustaining health and wellbeing of community members through citizen engagement, collaboration and partnerships. As a university and community-wide resource, OCEnR offers a variety of services and trainings to promote community engagement and recruitment in research. OCEnR has extensive experience in 
creating community advisory boards and conducting focus groups for variety conditions/topics with local and industry partners.

OCEnR works closely with the School of Social Work which has over 660 active community agency and organization partners through which undergraduate and graduate social work students are placed for internships. This diverse group of organizations includes, but is not limited to, community-based governmental entities, community-based not-for-profit groups, health care and mental health service providers, schools, and service providers for the elderly. OCEnR also works with the School of Medicine which partners with local, county and state public health departments. Capitalizing on these existing relationships will enable the PHOENIX project to more meaningfully, quickly and effectively engage with community members.

\section{Controversy \& Challenges}

\subsection{Promises \& Pitfalls of Precision Public Health}

Not everyone is keen on the idea of merging public health with concepts borrowed from precision medicine, especially when genomics is involved [63,98-100]. The utility of Precision Public Health has been questioned because its goals and strategies are not fundamentally different from those of traditional public health [101]. Moreover, there is concern "...that an unstinting focus on precision medicine by trusted spokespeople for health is a mistake - and a distraction from the goal of producing a healthier population" [101]. On the other hand, there is room for optimism if the recent pivot towards epidemiology and focus on social determinants [102] can produce demonstrable results that reinvigorate public health [99]. PHOENIX will increase the availability and accessibility of high-quality information on the distribution and determinants of health $-\mathrm{a}$ core public health function.

PHOENIX seeks to better understand the social determinants that underlie the geographic distribution of population-level health equity indicators. The focus on individual healthcare is also grounded in a population perspective; for instance, efforts to develop patient-level risk stratification tools will prioritize prevalent and costly health problems that are amendable to intervention (e.g., hypertension). PHOENIX is not predicated on genomics per se, although we seek to develop a system that can be used to evaluate potential health benefits of interventions and programs that may include genomic information. At the outset of our program, we expect that the integration of routinely collected data will be most informative about upstream [103] socialstructural factors that might modify public health programming and clinical care outcomes $[11,55]$.

\subsection{Data Quality \& Coverage}

Quality of information is critical in users' assessments and perceptions of HIE programs (i.e., healthcare professionals including administrators, clinicians, program supervisors and medical directors at organizations with care managers, social workers, patient navigators and health coaches who receive event notifications) [104]. Clinical information we will receive is primarily going to be shared from EHRs and thus could be subject to bias from fragmented data and selective ascertainment [17,105-107]. Furthermore, EHR data are limited compared to what is typically collected in prospective research studies [108]. Therefore, we will perform community screening events and supplement the shared data with program participant generated information; e.g., by 
incorporating new technologies (e.g., via smart phone applications) and capturing exposures that occur away from home [109]. We may additionally seek to develop services targeted towards lowincome residents aiming to strengthen the social safety-net (e.g., by working with local barber shops and salons [110]) [111]. Indeed, we are keen to avoid steps that may widen social disparities and/or potentially increase overdiagnosis $[18,68,112]$.

\subsection{Engagement \& Agency}

We do not yet know the best way to get social determinants information into the right hands to improve population-level health outcomes. Clinicians, government and elected officials, community organizations, and citizens all have a role to play and we are deliberately engaging each of these groups. Many physicians report that they do not have time or resources to consider social determinants [94]. Therefore, we are working with our health system and HIE partners to identify knowledge gaps and determine optimal strategies to incorporate such information into clinical practice (e.g., by developing strategies that incorporate nurses/pharmacists and streamline dissemination). To that end, as part of the CDC 1817 grant program and in collaboration with the Michigan Department of Health and Human Services, we are testing a pilot version of an application programming interface (API) that will make PHOENIX social determinant data readily available to clinicians within systemwide EHRs. Our dissemination strategy also relies heavily on community stakeholders with considerable agency; i.e., persons with motivation and ability to pursue, interpret and apply health information [113,114]. On the other hand, by establishing a surveillance system we also gain the capacity to evaluate the impact of low agency interventions (e.g., environmental policies, impact of community programs).

Collaborations with state and local health departments will help ensure that information from PHOENIX informs public health programming and response. To this end, we are working with local and state public health partners and other stakeholders to establish standard operating procedures including reporting protocols that are designed to optimize the utility of the information we generate. Together, our team will identify priority conditions, establish minimum reporting requirements, and develop templates for figures, tables and text that are in-line with local, state and national norms and policies. The initial demonstration of the

PHOENIX program in Southeastern Michigan will focus on priority conditions among those recently identified by the Detroit Health Department's community-engaged health assessment that have major public health implications across the lifespan (Table 2). 
$\underline{\text { Table 2. Baseline Priority Conditions }}$

\begin{tabular}{l} 
Cardiovascular Disease \\
\hline Hypertension (high blood pressure) \\
\hline Heart failure \\
Coronary heart disease (heart attack) \\
Cerebrovascular disease (stroke) \\
Mental Illness and Substance Use Disorders* \\
Diagnosable mental, behavioral or emotional disorder that \\
causes serious functional impairment that substantially limits \\
one or more major life activities (or child's functioning in \\
family, school or community activities) [e.g., depression, \\
anxiety, post-traumatic stress and borderline personality \\
disorders; schizophrenia].
\end{tabular}

Recurrent use of alcohol and/or drugs that causes clinically significant impairment, including health problems, disability, and failure to meet major responsibilities at work, school or home.

\begin{tabular}{l} 
Asthma \\
\hline Pediatric and adult \\
\hline Maternal Morbidity and Mortality \\
\hline Hypertensive pregnancy disorders (e.g., preeclampsia) \\
Preterm delivery \\
*adapted from the Substance Abuse and Mental Health Service \\
Administration
\end{tabular}

\subsection{Privacy}

Privacy is a critical concern. We will report information and share aggregated community-level information with appropriate protections as defined under BAA that ensure HIPAA compliance. We will share community-level health information with residents, public health and social service agencies as described above. Likewise, we will develop technical solutions to upload patient-level health information obtained with consent in the community to HIEs that can inform providers and payers to enable care coordination. We also envision working within defined BAA to access deidentified, limited use datasets to facilitate core public health functions, quality improvement initiatives, comparative effectiveness research and economic impact assessments as allowable under the HIPAA privacy rule (see [115] for explanation of public health and research accommodations).

\subsection{Sustainability}

Perhaps the greatest challenge is sustainability. Public health is markedly underfunded. Fewer than three percent of the U.S. healthcare budget is currently allocated towards public health [116]. 
Compared to peak spending in the wake of $9 / 11$ in 2002, public health's share of total U.S. health expenditures decreased by $17 \%$ as of 2014 and a decline of $25 \%$ is projected by 2023 . The decline in public health expenditures from 2008 to 2014 amounted to a $\$ 40$ billion loss in just six years. Consequently, many public health agencies are understaffed and ill-equipped to develop robust surveillance systems [117]. PHOENIX is one model of supporting local public health by partnering with university services supported by internal/extramural funds. Our goal is to be able to provide evidence of potential short- and long-term financial benefits of health programs. We also hope that disseminating the information will influence policy and programmatic decisions about support for public health and social service agencies in our community [117].

With the above understanding, development of financing mechanisms beyond reliance on university resources or extramural grant support is critical. A potential strategy may be for the PHOENIX program to collect fees from health systems, payers, investigators and other stakeholders for services involving advanced data integration and analytics. Users who pay a subscription fee would obtain restricted cloud access to de-identified and simulated datasets that are developed for specific use-case scenarios. All data would be manipulated in the cloud and no data would be exported to end users. Under this model, health systems, payers and investigators would pay in order to access population-level information and avoid costs related to data management and analytics. For stakeholders without such expertise, the PHOENIX team would conduct analyses on a fee for service basis. Early demonstrations would focus on 'hot spotting' [118], 'cold spotting' [119] and reducing waste in the healthcare system [120]. By focusing on analytics to enable population health management, we could expand the utility and impact of our HIE partners [121,122]. Moreover, if successful, this financing mechanism will sustain our ability to provide actional information to community members and public health/social service agencies at no cost.

We hope that the PHOENIX program framework will be scalable to other states across the nation that choose to adapt the model to their specific needs. In-turn, this would create a synchronous network that focuses on leveraging HIE to facilitate core public health activities in concert with a diverse array of national stakeholders.

\section{Conclusion}

Despite significant advances in disease specific therapies and on-going, substantial expenditures on healthcare in this country, U.S. life expectancy is declining. The plateau in mortality from conditions such as CVD has prompted calls for transformative research that emphasizes data integration, use of new technologies, implementation science and community participatory research [123]. The PHOENIX program was developed in direct response to these calls. PHOENIX will enhance chronic disease surveillance, establish bi-directional communication pathways with public health and social service agencies, target and evaluate the impact of community-based interventions, and facilitate community-engaged research. In doing so, PHOENIX expects to foster innovation and discovery of solutions that will better individual health and improve population-level outcomes. 


\section{Financial support:}

This work is supported by a grant from the Michigan Health Endowment Fund and by Wayne State University.

\section{Conflict of Interest Statement:}

The authors report no conflict of interest, financial or otherwise.

\section{REFERENCES}

1. Narayan KMV, Patel SA, Cunningham SA, Curran J. 2019. Ominous Reversal of Health Gains in the United States: Time to Rethink Research Priorities? Ann Intern Med. 170(5), 330-31. Epub 02 2019. doi:https://doi.org/10.7326/M18-3653. PubMed

2. Anderson GF, Hussey P, Petrosyan V. 2019. It's Still The Prices, Stupid: Why The US Spends So Much On Health Care, And A Tribute To Uwe Reinhardt. Health Aff (Millwood). 38(1), 87-95. Epub 01 2019. doi:https://doi.org/10.1377/hlthaff.2018.05144. PubMed

3. Woolf SH, Aron LY. 2013. The US health disadvantage relative to other high-income countries: findings from a National Research Council/Institute of Medicine report. JAMA. 309(8), 771-72. Epub 01 2013. doi:https://doi.org/10.1001/jama.2013.91. PubMed

4. Council NR. Population Co. US health in international perspective: Shorter lives, poorer health: National Academies Press; 2013.

5. Xu JQ, Murphy SL, Kochanek KD, Arias E. Mortality in the United States, 2015. NCHS data brief, no 267. Hyattsville, MD: National Center for Health Statistics. 2016.

6. Kochanek K, Murphy S, Xu J, Arias E. Mortality in the United States, 2016. NCHS Data Brief, no 293. National Center for Health Statistics. 2017.

7. Control CfD, Prevention. Multiple cause of death 1999-2017 on CDC WONDER online Database, released December, 2018. Data are from the Multiple cause of death Files, 19992017 as compiled from data provided by the 57 vital statistics jurisdictions through the vital Statistics cooperative Program2018.

8. Yusuf S, Joseph P, Rangarajan S, Islam S, Mente A, et al. 2019. Modifiable risk factors, cardiovascular disease, and mortality in 155722 individuals from 21 high-income, middleincome, and low-income countries (PURE): a prospective cohort study. Lancet. 395(10226):795-808. Epub 09 2019. doi:10.1016/S0140-6736(19)32008-2. PubMed

9. Dwyer-Lindgren L, Bertozzi-Villa A, Stubbs RW, Morozoff C, Mackenbach JP, et al. 2017. Inequalities in Life Expectancy Among US Counties, 1980 to 2014: Temporal Trends and Key Drivers. JAMA Intern Med. 177(7), 1003-11. Epub 052017. doi:https://doi.org/10.1001/jamainternmed.2017.0918. PubMed 
10. Hero JO, Zaslavsky AM, Blendon RJ. 2017. The United States Leads Other Nations In Differences By Income In Perceptions Of Health And Health Care. Health Aff (Millwood). 36(6), 1032-40. Epub 06 2017. doi:https://doi.org/10.1377/hlthaff.2017.0006. PubMed

11. Diez Roux AV, Katz M, Crews DC, Ross D, Adler N. 2015. Social and Behavioral Information in Electronic Health Records: New Opportunities for Medicine and Public Health. Am J Prev Med. 49(6), 980-83. Epub 112015. doi:https://doi.org/10.1016/j.amepre.2015.08.027. PubMed

12. Social IoMCotR. Domains B, Records MfEH. Capturing social and behavioral domains and measures in electronic health records: phase 2: National Academies Press; 2014.

13. Huffstetler AN, Phillips RL, Jr. Payment Structures That Support Social Care Integration With Clinical Care: Social Deprivation Indices and Novel Payment Models. Am J Prev Med. 2019;57(6S1):S82-S8. Epub 2019/11/23. doi: 10.1016/j.amepre.2019.07.011. PubMed PMID: 31753283.

14. Mensah GA, Cooper RS, Siega-Riz AM, Cooper LA, Smith JD, et al. 2018. Reducing Cardiovascular Disparities Through Community-Engaged Implementation Research: A National Heart, Lung, and Blood Institute Workshop Report. Circ Res. 122(2), 213-30. Epub 01 2018. doi:https://doi.org/10.1161/CIRCRESAHA.117.312243. PubMed

15. Sadler RC, Hippensteel C, Nelson V, Greene-Moton E, Furr-Holden CD. 2019. Communityengaged development of a GIS-based healthfulness index to shape health equity solutions. Soc Sci Med. 227, 63-75. Epub 072018. doi:https://doi.org/10.1016/j.socscimed.2018.07.030. PubMed

16. Vest JR, Menachemi N, Grannis SJ, Ferrell JL, Kasthurirathne SN, et al. 2019. Impact of Risk Stratification on Referrals and Uptake of Wraparound Services That Address Social Determinants: A Stepped Wedged Trial. Am J Prev Med. 56(4), e125-33. Epub 022019. doi:https://doi.org/10.1016/j.amepre.2018.11.009. PubMed

17. Cottrell EK, Dambrun K, Cowburn S, Mossman N, Bunce AE, Marino M, Krancari M, Gold R. Variation in Electronic Health Record Documentation of Social Determinants of Health Across a National Network of Community Health Centers. Am J Prev Med. 2019;57(6S1):S65-S73. Epub 2019/11/23. doi: 10.1016/j.amepre.2019.07.014. PubMed PMID: 31753281.

18. Fichtenberg CM, Alley DE, Mistry KB. Improving Social Needs Intervention Research: Key Questions for Advancing the Field. Am J Prev Med. 2019;57(6S1):S47-S54. Epub 2019/11/23. doi: 10.1016/j.amepre.2019.07.018. PubMed PMID: 31753279.

19. Gottlieb LM, DeSalvo K, Adler NE. Healthcare Sector Activities to Identify and Intervene on Social Risk: An Introduction to the American Journal of Preventive Medicine Supplement. Am J Prev Med. 2019;57(6S1):S1-S5. Epub 2019/11/23. doi: 10.1016/j.amepre.2019.07.009. PubMed PMID: 31753275. 
20. Krist AH, Davidson KW, Ngo-Metzger Q, Mills J. Social Determinants as a Preventive Service: U.S. Preventive Services Task Force Methods Considerations for Research. Am J Prev Med. 2019;57(6S1):S6-S12. Epub 2019/11/23. doi: 10.1016/j.amepre.2019.07.013. PubMed PMID: 31753280.

21. Meurer JR, Whittle JC, Lamb KM, Kosasih MA, Dwinell MR, et al. 2019. Precision Medicine and Precision Public Health: Academic Education and Community Engagement. Am J Prev Med. 57(2), 286-89. Epub 072019. doi:https://doi.org/10.1016/j.amepre.2019.03.010. PubMed

22. Valdiserri RO. Improving Public Health Practice Capacity in Governmental Settings: A Proposal [Internet]: Health Affairs Blog. 1/23/2020. [cited 2020]. Available from: DOI: 10.1377/hblog20200117.183001 https://www.healthaffairs.org/do/10.1377/hblog20200117.183001/full/

23. Susser M, Stein Z. Eras in epidemiology: the evolution of ideas: Oxford University Press; 2009.

24. Morabia A. 2015. Has epidemiology become infatuated with methods? A historical perspective on the place of methods during the classical (1945-1965) phase of epidemiology. Annu Rev Public Health. 36, 69-88. Epub 01 2015. doi:https://doi.org/10.1146/annurevpublhealth-031914-122403. PubMed

25. Bush V. 1903. Science: The endless frontier. Trans Kans Acad Sci. 1945, 231-64.

26. Cooper RS. 2018. Control of Cardiovascular Disease in the 20th Century: Meeting the Challenge of Chronic Degenerative Disease. Perspect Biol Med. 61(4), 550-59. Epub 01 2019. doi:https://doi.org/10.1353/pbm.2018.0064. PubMed

27. Ford ES, Ajani UA, Croft JB, Critchley JA, Labarthe DR, et al. 2007. Explaining the decrease in U.S. deaths from coronary disease, 1980-2000. N Engl J Med. 356(23), 2388-98. Epub 06 2007. doi:https://doi.org/10.1056/NEJMsa053935. PubMed

28. Lopez AD, Adair T. 2019. Is the long-term decline in cardiovascular-disease mortality in high-income countries over? Evidence from national vital statistics. Int J Epidemiol. 48(6), 1815-23. Epub 08 2019. doi:https://doi.org/10.1093/ije/dyz143. PubMed

29. Mensah GA, Wei GS, Sorlie PD, Fine LJ, Rosenberg Y, et al. 2017. Decline in Cardiovascular Mortality: Possible Causes and Implications. Circ Res. 120(2), 366-80. Epub 01 2017. doi:https://doi.org/10.1161/CIRCRESAHA.116.309115. PubMed

30. Shah NS, Lloyd-Jones DM, O’Flaherty M, Capewell S, Kershaw KN, et al. 2019. Trends in Cardiometabolic Mortality in the United States, 1999-2017. JAMA. 322(8), 780-82. Epub 08 2019. doi:https://doi.org/10.1001/jama.2019.9161. PubMed

31. Krieger N, Rehkopf DH, Chen JT, Waterman PD, Marcelli E, et al. 2008. The fall and rise of US inequities in premature mortality: 1960-2002. PLoS Med. 5(2), e46. Epub 022008. doi:https://doi.org/10.1371/journal.pmed.0050046. PubMed 
32. Mensah GA, Goff DC, Gibbons GH. 2017. Cardiovascular Mortality Differences-Place Matters. JAMA. 317(19), 1955-57. Epub 052017. doi:https://doi.org/10.1001/jama.2017.4168. PubMed

33. Roth GA, Dwyer-Lindgren L, Bertozzi-Villa A, Stubbs RW, Morozoff C, et al. 2017. Trends and Patterns of Geographic Variation in Cardiovascular Mortality Among US Counties, 1980-2014. JAMA. 317(19), 1976-92. Epub 052017. doi:https://doi.org/10.1001/jama.2017.4150. PubMed

34. Solar O, Irwin A. A conceptual framework for action on the social determinants of health. Social Determinants of Health Discussion Paper 2 (Policy and Practice). Geneva: 2010.

35. Malats N, Castano-Vinyals G. 2007. Cancer epidemiology: study designs and data analysis. Clin Transl Oncol. 9(5), 290-97. Epub 05 2007. doi:https://doi.org/10.1007/s12094-007$\underline{0056-x} . \underline{\text { PubMed }}$

36. Dammann O, Gray P, Gressens P, Wolkenhauer O, Leviton A. 2014. Systems Epidemiology: What's in a Name? Online J Public Health Inform. 6(3), e198. Epub 01 2015. doi:https://doi.org/10.5210/ojphi.v6i3.5571. PubMed

37. Irwin A, Scali E. Action on the Social Determinants of Health: learning from previous experiences. Social Determinants of Health Discussion Paper 1 (Debates). Geneva: World Health Organization, 2010.

38. Strohman RC. 1997. The coming Kuhnian revolution in biology. Nat Biotechnol. 15(3), 194200. Epub 03 1997. doi:https://doi.org/10.1038/nbt0397-194. PubMed

39. Paneth N, Vermund SH. 2018. Human Molecular Genetics Has Not Yet Contributed to Measurable Public Health Advances. Perspect Biol Med. 61(4), 537-49. Epub 012019. doi:https://doi.org/10.1353/pbm.2018.0063. PubMed

40. Casadevall A. 2018. Is the Pace of Biomedical Innovation Slowing? Perspect Biol Med. 61(4), 584-93. Epub 01 2019. doi:https://doi.org/10.1353/pbm.2018.0067. PubMed

41. Hyder A. 2018. Public Funding for Genomics and the Return on Investment: A Public Health Perspective. Perspect Biol Med. 61(4), 572-83. Epub 012019. doi:https://doi.org/10.1353/pbm.2018.0066. PubMed

42. Kaufman JS, Dolman L, Rushani D, Cooper RS. 2015. The contribution of genomic research to explaining racial disparities in cardiovascular disease: a systematic review. Am J Epidemiol. 181(7), 464-72. Epub 03 2015. doi:https://doi.org/10.1093/aje/kwu319. PubMed

43. Clyne M, Schully SD, Dotson WD, Douglas MP, Gwinn M, et al. 2014. Horizon scanning for translational genomic research beyond bench to bedside. Genet Med. 16(7), 535-38. Epub 01 2014. doi:https://doi.org/10.1038/gim.2013.184. PubMed 
44. Khoury MJ. 2010. Dealing with the evidence dilemma in genomics and personalized medicine. Clin Pharmacol Ther. 87(6), 635-38. Epub 052010. doi:https://doi.org/10.1038/clpt.2010.4. PubMed

45. Butler D. 2008. Translational research: crossing the valley of death. Nature 453(7197), 84042. Epub 06 2008. doi:https://doi.org/10.1038/453840a. PubMed

46. Interlandi J. The Paradox of Precision Medicine. Sci Am. 2016;314(4):24, B. Epub 2016/04/16. doi: 10.1038/scientificamerican0416-24. PubMed PMID: 27082186.

47. Kimmelman J, Tannock I. 2018. The paradox of precision medicine. Nat Rev Clin Oncol. 15(6), 341-42. Epub 04 2018. doi:https://doi.org/10.1038/s41571-018-0016-0. PubMed

48. All of Us Research Program I, Denny JC, Rutter JL, Goldstein DB, Philippakis A, Smoller JW, Jenkins G, Dishman E. 2019. The "All of Us" Research Program. N Engl J Med. 381(7), 668-76. Epub 08 2019. doi:10.1056/NEJMsr1809937. PubMed

49. Khoury MJ, Gwinn M, Clyne M, Yu W. 2011. Genetic epidemiology with a capital E, ten years after. Genet Epidemiol. 35(8), 845-52. Epub 112011.

doi:https://doi.org/10.1002/gepi.20634. PubMed

50. Khoury MJ, Gwinn M, Ioannidis JP. 2010. The emergence of translational epidemiology: from scientific discovery to population health impact. Am J Epidemiol. 172(5), 517-24. Epub 08 2010. doi:https://doi.org/10.1093/aje/kwq211. PubMed

51. Weeramanthri TS, Dawkins HJS, Baynam G, Bellgard M, Gudes O, et al. 2018. Editorial: Precision Public Health. Front Public Health. 6(121), 121. Epub 052018. doi:10.3389/fpubh.2018.00121. PubMed

52. Khoury MJ, Iademarco MF, Riley WT. 2016. Precision Public Health for the Era of Precision Medicine. Am J Prev Med. 50(3), 398-401. Epub 112015. doi:https://doi.org/10.1016/j.amepre.2015.08.031. PubMed

53. Khoury MJ, Lam TK, Ioannidis JP, Hartge P, Spitz MR, et al. 2013. Transforming epidemiology for 21st century medicine and public health. Cancer Epidemiol Biomarkers Prev. 22(4), 508-16. Epub 03 2013. doi:https://doi.org/10.1158/1055-9965.EPI-13-0146. $\underline{\text { PubMed }}$

54. Dowell SF, Blazes D, Desmond-Hellmann S. Four steps to precision public health. Nature. 2016;540(7632):189-91. doi: DOI 10.1038/540189a. PubMed PMID: WOS:000389548700020.

55. Khoury MJ, Ioannidis JP. 2014. Medicine. Big data meets public health. Science. 346(6213), 1054-55. Epub 11 2014. doi:https://doi.org/10.1126/science.aaa2709. PubMed

56. Ioannidis JPA, Khoury MJ. 2018. Evidence-based medicine and big genomic data. Hum Mol Genet. 27(R1), R2-7. Epub 02 2018. doi:https://doi.org/10.1093/hmg/ddy065. PubMed 
57. Khoury MJ, Bowen MS, Clyne M, Dotson WD, Gwinn ML, et al. 2018. From public health genomics to precision public health: a 20-year journey. Genet Med. 20(6), 574-82. Epub 12 2017. doi:https://doi.org/10.1038/gim.2017.211. PubMed

58. Thacker SB, Berkelman RL. 1988. Public health surveillance in the United States. Epidemiol Rev. 10, 164-90. Epub 011988.

doi:https://doi.org/10.1093/oxfordjournals.epirev.a036021. PubMed

59. Koplan JP, Milstein R, Wetterhall S. 1999. Framework for program evaluation in public health. MMWR Recomm Rep. 48, 1-40. PubMed

60. Prosperi M, Min JS, Bian J, Modave F. 2018. Big data hurdles in precision medicine and precision public health. BMC Med Inform Decis Mak. 18(1), 139. Epub 122018. doi:https://doi.org/10.1186/s12911-018-0719-2. PubMed

61. Juarez PD, Matthews-Juarez P, Hood DB, Im W, Levine RS, et al. 2014. The public health exposome: a population-based, exposure science approach to health disparities research. Int J Environ Res Public Health. 11(12), 12866-95. Epub 122014. doi:https://doi.org/10.3390/ijerph111212866. PubMed

62. Seneviratne MG, Kahn MG, Hernandez-Boussard T. 2019. Merging heterogeneous clinical data to enable knowledge discovery. Pac Symp Biocomput. 24, 439-43. Epub 032019. $\underline{\text { PubMed }}$

63. Kenney M, Mamo L. 2019. The imaginary of precision public health. Med Humanit. •••. Epub 08 2019. doi:https://doi.org/10.1136/medhum-2018-011597. PubMed

64. Lipworth W, Mason PH, Kerridge I, Ioannidis JPA. 2017. Ethics and Epistemology in Big Data Research. J Bioeth Inq. 14(4), 489-500. Epub 032017. doi:https://doi.org/10.1007/s11673-017-9771-3. PubMed

65. Calude CS, Longo G. 2016. The Deluge of Spurious Correlations in Big Data. Found Sci. 118.

66. Manrai AK, Patel CJ, Ioannidis JPA. 2018. In the Era of Precision Medicine and Big Data, Who Is Normal? JAMA. 319(19), 1981-82. Epub 052018. doi:https://doi.org/10.1001/jama.2018.2009. PubMed

67. Khoury MJ, Engelgau M, Chambers DA, Mensah GA. 2018. Beyond Public Health Genomics: Can Big Data and Predictive Analytics Deliver Precision Public Health? Public Health Genomics. 21(5-6), 244-50. Epub 07 2019. doi:https://doi.org/10.1159/000501465. $\underline{\text { PubMed }}$

68. Vogt H, Green S, Ekstrom CT, Brodersen J. 2019. How precision medicine and screening with big data could increase overdiagnosis. BMJ. 366, 15270. Epub 092019. doi:https://doi.org/10.1136/bmj.15270. PubMed 
69. Fiedorowicz JG, Ioannidis JPA. 2019. Are all mental disorders related to all other medical diseases and vice versa? J Psychosom Res. 118, 71-72. Epub 022019. doi:https://doi.org/10.1016/j.jpsychores.2019.01.018. PubMed

70. Remington PL, Catlin BB, Gennuso KP. 2015. The County Health Rankings: rationale and methods. Popul Health Metr. 13, 11. Epub 05 2015. doi:https://doi.org/10.1186/s12963-0150044-2. PubMed

71. Control CfD. Prevention, Control CfD, Prevention. 500 cities: local data for better health. Atlanta, GA: Centers for Disease Control and Prevention; 2017.

72. Gebreab SY, Davis SK, Symanzik J, Mensah GA, Gibbons GH, et al. 2015. Geographic variations in cardiovascular health in the United States: contributions of state- and individual-level factors. J Am Heart Assoc. 4(6), e001673. Epub 052015. doi:https://doi.org/10.1161/JAHA.114.001673. PubMed

73. 2019. Seeking precision in public health. Nat Med. 25(8), 1177. Epub 082019. doi:https://doi.org/10.1038/s41591-019-0556-6. PubMed

74. Beck AF, Sandel MT, Ryan PH, Kahn RS. 2017. Mapping Neighborhood Health Geomarkers To Clinical Care Decisions To Promote Equity In Child Health. Health Aff (Millwood). 36(6), 999-1005. Epub 06 2017. doi:https://doi.org/10.1377/hlthaff.2016.1425. $\underline{\text { PubMed }}$

75. Wei X, Zhou L, Zhang Z, Chen Z, Zhou Y. 2019. Early prediction of epileptic seizures using a long-term recurrent convolutional network. J Neurosci Methods. 327, 108395. Epub 08 2019. doi:https://doi.org/10.1016/j.jneumeth.2019.108395. PubMed

76. Zhao L, Chen J, Chen F, Wang W, Lu CT, et al. 2015. SimNest: Social Media Nested Epidemic Simulation via Online Semi-supervised Deep Learning. Proc IEEE Int Conf Data Min. 2015, 639-48. Epub 07 2016. doi:10.1109/ICDM.2015.39. PubMed

77. Sampson UKA, Kaplan RM, Cooper RS, Diez Roux AV, Marks JS, et al. 2016. Reducing Health Inequities in the U.S.: Recommendations From the NHLBI's Health Inequities Think Tank Meeting. J Am Coll Cardiol. 68(5), 517-24. Epub 072016. doi:https://doi.org/10.1016/j.jacc.2016.04.059. PubMed

78. Vest JR, Harle CA, Schleyer T, Dixon BE, Grannis SJ, et al. 2016. Getting from here to there: health IT needs for population health. Am J Manag Care. 22(12), 827-29. Epub 12 2016. PubMed

79. Levy PD. 2019. Whose Job Is it Anyway? Acad Emerg Med. 26(5), 584-86. Epub 042019. doi:https://doi.org/10.1111/acem.13762. PubMed

80. Basu S, Siddiqi A. 2014. Geographic disparities in US mortality: "hot-spotting" large databases. Epidemiology. 25(3), 468-70. Epub 042014. doi:https://doi.org/10.1097/EDE.0000000000000085. PubMed 
81. Rahimian F, Salimi-Khorshidi G, Payberah AH, Tran J, Ayala Solares R, Raimondi F, Nazarzadeh M, Canoy D, Rahimi K. Predicting the risk of emergency admission with machine learning: Development and validation using linked electronic health records. PLoS Med. 2018;15(11):e1002695. Epub 2018/11/21. doi: 10.1371/journal.pmed.1002695. PubMed PMID: 30458006; PMCID: PMC6245681 following competing interests: JT receives funding for DPhil provided by Rhodes Trust and Clarendon Fund, is Chair on board of CHASE (incorporated association), travel grant from European Society of Hypertension, British Research Council training grant, Special Consultant for Bendelta. KR receives a stipend as a specialty consulting editor for PLOS Medicine and serves on the journal's editorial board.

82. Ye C, Fu T, Hao S, Zhang Y, Wang O, et al. 2018. Prediction of Incident Hypertension Within the Next Year: Prospective Study Using Statewide Electronic Health Records and Machine Learning. J Med Internet Res. 20(1), e22. Epub 022018. doi:https://doi.org/10.2196/jmir.9268. PubMed

83. Li X, Zhu D, Levy P. 2018. Leveraging auxiliary measures: a deep multi-task neural network for predictive modeling in clinical research. BMC Med Inform Decis Mak. 18(Suppl 4), 126. Epub 12 2018. doi:https://doi.org/10.1186/s12911-018-0676-9. PubMed

84. Ayala Solares JR, Canoy D, Raimondi FED, Zhu Y, Hassaine A, et al. 2019. Long-Term Exposure to Elevated Systolic Blood Pressure in Predicting Incident Cardiovascular Disease: Evidence From Large-Scale Routine Electronic Health Records. J Am Heart Assoc. 8(12), e012129. Epub 06 2019. doi:https://doi.org/10.1161/JAHA.119.012129. PubMed

85. Lacson RC, Baker B, Suresh H, Andriole K, Szolovits P, et al. 2019. Use of machinelearning algorithms to determine features of systolic blood pressure variability that predict poor outcomes in hypertensive patients. Clin Kidney J. 12(2), 206-12. Epub 042019. doi:https://doi.org/10.1093/ckj/sfy049. PubMed

86. Park J, Kim JW, Ryu B, Heo E, Jung SY, et al. 2019. Patient-Level Prediction of CardioCerebrovascular Events in Hypertension Using Nationwide Claims Data. J Med Internet Res. 21(2), e11757. Epub 02 2019. doi:https://doi.org/10.2196/11757. PubMed

87. Sakr S, Elshawi R, Ahmed A, Qureshi WT, Brawner C, et al. 2018. Using machine learning on cardiorespiratory fitness data for predicting hypertension: The Henry Ford ExercIse Testing (FIT) Project. PLoS One. 13(4), e0195344. Epub 042018. doi:https://doi.org/10.1371/journal.pone.0195344. PubMed

88. Khanji C, Lalonde L, Bareil C, Lussier MT, Perreault S, et al. 2019. Lasso Regression for the Prediction of Intermediate Outcomes Related to Cardiovascular Disease Prevention Using the TRANSIT Quality Indicators. Med Care. 57(1), 63-72. Epub 112018. doi:https://doi.org/10.1097/MLR.0000000000001014. PubMed

89. Li X, Zhu D, Levy P. 2020. Predicting clinical outcomes with patient stratification via deep mixture neural networks. AMIA Jt Summits Transl Sci Proc. (In press). 
90. Christodoulou E, Ma J, Collins GS, Steyerberg EW, Verbakel JY, et al. 2019. A systematic review shows no performance benefit of machine learning over logistic regression for clinical prediction models. J Clin Epidemiol. 110, 12-22. Epub 022019. doi:https://doi.org/10.1016/j.jclinepi.2019.02.004. PubMed

91. Li X, Zhu D, Dong M, Zafar Nezhad M, Janke A, et al. 2017. SDT: A Tree Method for Detecting Patient Subgroups with Personalized Risk Factors. AMIA Jt Summits Transl Sci Proc. 2017, 193-202. Epub 08 2017. PubMed

92. Desai RJ, Wang SV, Vaduganathan M, Evers T, Schneeweiss S. 2020. Comparison of Machine Learning Methods With Traditional Models for Use of Administrative Claims With Electronic Medical Records to Predict Heart Failure Outcomes. JAMA Netw Open. 3(1), e1918962. Epub 01 2020. doi:https://doi.org/10.1001/jamanetworkopen.2019.18962. PubMed

93. Kasthurirathne SN, Vest JR, Menachemi N, Halverson PK, Grannis SJ. 2018. Assessing the capacity of social determinants of health data to augment predictive models identifying patients in need of wraparound social services. J Am Med Inform Assoc. 25(1), 47-53. Epub 11 2017. doi:https://doi.org/10.1093/jamia/ocx130. PubMed

94. Davidson KW, McGinn T. 2019. Screening for Social Determinants of Health: The Known and Unknown. JAMA. 322(11):1037-1038. Epub 082019. doi:https://doi.org/10.1001/jama.2019.10915. PubMed

95. Martyn C. 2014. Risky business: doctors' understanding of statistics. BMJ. 349, g5619. Epub 09 2014. doi:https://doi.org/10.1136/bmj.g5619. PubMed

96. Järvinen TL. 2016. Labelling people as 'High Risk': A tyranny of eminence? Br J Sports Med. 50 (2), 77-78. Epub 11 2015. doi:https://doi.org/10.1136/bjsports-2015-095286. $\underline{\text { PubMed }}$

97. Bartlett G, Gagnon J. 2016. Physicians and knowledge translation of statistics: Mind the gap. CMAJ. 188(1), 11-12. Epub 12 2015. doi:https://doi.org/10.1503/cmaj.151254. PubMed

98. Taylor-Robinson D, Kee F. 2019. Precision public health-the Emperor's new clothes. Int J Epidemiol. 48(1), 1-6. Epub 09 2018. doi:https://doi.org/10.1093/ije/dyy184. PubMed

99. Chowkwanyun M, Bayer R, Galea S. 2018. "Precision” Public Health - Between Novelty and Hype. N Engl J Med. 379(15), 1398-400. Epub 092018. doi:https://doi.org/10.1056/NEJMp1806634. PubMed

100. Chowkwanyun M, Bayer R, Galea S. 2019. Precision public health: pitfalls and promises. Lancet. 393(10183), 1801. Epub 05 2019. doi:https://doi.org/10.1016/S0140$\underline{6736(18) 33187-8}$. PubMed

101. Bayer R, Galea S. 2015. Public Health in the Precision-Medicine Era. N Engl J Med. 373(6), 499-501. Epub 08 2015. doi:https://doi.org/10.1056/NEJMp1506241. PubMed 
102. Olstad DL, McIntyre L. 2019. Reconceptualising precision public health. BMJ Open. 9(9), e030279. Epub 09 2019. doi:https://doi.org/10.1136/bmjopen-2019-030279. PubMed

103. Lantz PM. 2019. The Medicalization of Population Health: Who Will Stay Upstream? Milbank Q. 97(1), 36-39. Epub 12 2018. doi:https://doi.org/10.1111/1468-0009.12363. $\underline{\text { PubMed }}$

104. Vest JR, Ancker JS. 2017. Health information exchange in the wild: the association between organizational capability and perceived utility of clinical event notifications in ambulatory and community care. J Am Med Inform Assoc. 24(1), 39-46. Epub 042016.

doi:https://doi.org/10.1093/jamia/ocw040. PubMed

105. Galea S, Abdalla SM. 2018. Precision Medicine Approaches and the Health of Populations: Study Design Concerns and Considerations. Perspect Biol Med. 61(4), 527-36. Epub 01 2019. doi:https://doi.org/10.1353/pbm.2018.0062. PubMed

106. Wei WQ, Leibson CL, Ransom JE, Kho AN, Caraballo PJ, et al. 2012. Impact of data fragmentation across healthcare centers on the accuracy of a high-throughput clinical phenotyping algorithm for specifying subjects with type 2 diabetes mellitus. J Am Med Inform Assoc. 19(2), 219-24. Epub 01 2012. doi:https://doi.org/10.1136/amiajnl-2011000597. PubMed

107.Hemkens LG, Contopoulos-Ioannidis DG, Ioannidis JPA. 2016. Routinely collected data and comparative effectiveness evidence: promises and limitations. CMAJ. 188(8), E158-64. Epub 02 2016. doi:https://doi.org/10.1503/cmaj.150653. PubMed

108. Bartlett VL, Dhruva SS, Shah ND, Ryan P, Ross JS. 2019. Feasibility of Using Real-World Data to Replicate Clinical Trial Evidence. JAMA Netw Open. 2(10), e1912869. Epub 10 2019. doi:https://doi.org/10.1001/jamanetworkopen.2019.12869. PubMed

109. Tamura K, Langerman SD, Ceasar JN, Andrews MR, Agrawal M, et al. 2019. Neighborhood Social Environment and Cardiovascular Disease Risk. Curr Cardiovasc Risk Rep. 13(4). Epub 09 2019. doi:https://doi.org/10.1007/s12170-019-0601-5. PubMed

110. Victor RG, Lynch K, Li N, Blyler C, Muhammad E, et al. 2018. A Cluster-Randomized Trial of Blood-Pressure Reduction in Black Barbershops. N Engl J Med. 378(14), 1291-301. Epub 03 2018. doi:https://doi.org/10.1056/NEJMoa1717250. PubMed

111. Vaida BL, for the Uninsured In Memphis. 2019. A Stronger Safety Net. Health Aff (Millwood). 38(9), 1420-24. Epub 09 2019. doi:https://doi.org/10.1377/hlthaff.2019.00999. $\underline{\text { PubMed }}$

112. Burris HH, Wright CJ, Kirpalani H, Collins JW, Jr, Lorch SA, et al. 2019. The promise and pitfalls of precision medicine to resolve black-white racial disparities in preterm birth. Pediatr Res. Epub 08 2019. doi:10.1038/s41390-019-0528-z. PubMed 
113. Capewell S, Graham H. 2010. Will cardiovascular disease prevention widen health inequalities? PLoS Med. 7(8), e1000320. Epub 092010.

doi:https://doi.org/10.1371/journal.pmed.1000320. PubMed

114.Adams J, Mytton O, White M, Monsivais P. 2016. Why Are Some Population Interventions for Diet and Obesity More Equitable and Effective Than Others? The Role of Individual Agency. PLoS Med. 13(4), e1001990. Epub 042016. doi:https://doi.org/10.1371/journal.pmed.1001990. PubMed

115. Gostin LO, Levit LA, Nass SJ. Beyond the HIPAA privacy rule: enhancing privacy, improving health through research: National Academies Press; 2009.

116. Himmelstein DU, Woolhandler S. 2016. Public Health's Falling Share of US Health Spending. Am J Public Health. 106(1), 56-57. Epub 112015. doi:https://doi.org/10.2105/AJPH.2015.302908. PubMed

117. Teutsch SM, Fielding J. 2016. Economics and Local Public Health Departments. Am J Prev Med. 50(5) (Suppl 1), S81-3. Epub 042016. doi:https://doi.org/10.1016/j.amepre.2015.10.011. PubMed

118. Gawande A. 2011. The hot spotters. New Yorker. 40-51 . $\underline{\text { PubMed }}$

119. Westfall JM. 2013. Cold-spotting: linking primary care and public health to create communities of solution. J Am Board Fam Med. 26(3), 239-40. Epub 052013. doi:https://doi.org/10.3122/jabfm.2013.03.130094. PubMed

120. Shrank WH, Rogstad TL, Parekh N. 2019. Waste in the US Health Care System: Estimated Costs and Potential for Savings. JAMA. 322(15):1501-1509. Epub 102019.

doi:https://doi.org/10.1001/jama.2019.13978. PubMed

121. Menachemi N, Rahurkar S, Harle CA, Vest JR. 2018. The benefits of health information exchange: an updated systematic review. J Am Med Inform Assoc. 25(9), 1259-65. Epub 05 2018. doi:https://doi.org/10.1093/jamia/ocy035. PubMed

122. Yeager VA, Vest JR, Walker D, Diana ML, Menachemi N. 2017. Challenges to Conducting Health Information Exchange Research and Evaluation: Reflections and Recommendations for Examining the Value of HIE. EGEMS (Wash DC). 5(1), 15. Epub 062018. doi:https://doi.org/10.5334/egems.217. PubMed

123.Dzau VJ, Balatbat CA. 2019. Future of Hypertension. Hypertension. 74(3), 450-57. Epub 07 2019. doi:https://doi.org/10.1161/HYPERTENSIONAHA.119.13437. PubMed 